\title{
Simulation Evaluation of Synthetic Vision as an Enabling Technology for Equivalent Visual Operations
}

\author{
Lynda J. Kramer*, Steven P. Williams, and Randall E. Bailey \\ NASA Langley Research Center, M/S 152, Hampton, VA 23681-0001
}

\begin{abstract}
Enhanced Vision (EV) and synthetic vision (SV) systems may serve as enabling technologies to meet the challenges of the Next Generation Air Transportation System (NextGen) Equivalent Visual Operations (EVO) concept - that is, the ability to achieve or even improve on the safety of Visual Flight Rules (VFR) operations, maintain the operational tempos of VFR, and even, perhaps, retain VFR procedures independent of actual weather and visibility conditions. One significant challenge lies in the definition of required equipage on the aircraft and on the airport to enable the EVO concept objective. A piloted simulation experiment was conducted to evaluate the effects of the presence or absence of Synthetic Vision, the location of this information during an instrument approach (i.e., on a Head-Up or Head-Down Primary Flight Display), and the type of airport lighting information on landing minima. The quantitative data from this experiment were analyzed to begin the definition of performance-based criteria for all-weather approach and landing operations. Objective results from the present study showed that better approach performance was attainable with the head-up display (HUD) compared to the head-down display (HDD). A slight performance improvement in HDD performance was shown when SV was added, as the pilots descended below $200 \mathrm{ft}$ to a $100 \mathrm{ft}$ decision altitude, but this performance was not tested for statistical significance (nor was it expected to be statistically significant). The touchdown data showed that regardless of the display concept flown (SV HUD, Baseline HUD, SV HDD, Baseline HDD) a majority of the runs were within the performance-based defined approach and landing criteria in all the visibility levels, approach lighting systems, and decision altitudes tested. For this visual flight maneuver, RVR appeared to be the most significant influence in touchdown performance. The approach lighting system clearly impacted the pilot's ability to descend to $100 \mathrm{ft}$ height above touchdown based on existing Federal Aviation Regulation (FAR) 91.175 using a $200 \mathrm{ft}$ decision height, but did not appear to influence touchdown performance or approach path maintenance.
\end{abstract}

Keywords: Synthetic Vision System, Head-Up Display, Global Positioning System, Aviation Safety, Next Generation Air Transportation System, Approach Lighting System, Equivalent Visual Operations

\section{INTRODUCTION}

The Integrated Intelligent Flight Deck Technologies (IIFDT) project, under NASA's Aviation Safety Program (AvSP), comprises a multi-disciplinary research effort to develop flight deck technologies that mitigate operator-, automation-, and environment-induced hazards. Towards this objective, IIFDT is developing crew/vehicle interface technologies that reduce the propensity for pilot error, minimize the risks associated with pilot error, and proactively overcome aircraft safety barriers that would otherwise constrain the full realization of the next generation air transportation system (NextGen). ${ }^{1}$ Part of this research effort involves the use of enhanced and synthetic vision systems and other interface modalities as enabling technologies to meet the challenges of an Equivalent Visual Operations (EVO) concept - that is, the ability to achieve or even improve on the safety of Visual Flight Rules (VFR) operations, maintain the operational tempos of VFR, and even, perhaps, retain VFR procedures independent of actual weather and visibility conditions.

One significant challenge to the EVO concept objective is the definition of required equipage on the aircraft and on the airport. With today's equipment and regulations, significant investment is required in on-board equipment for navigation, surveillance, and flight control and on the airport for precision guidance systems and approach lighting systems for "all-weather" landing capability. The levels of equipment redundancy, capability, and accuracy dramatically increase as landing visibility minima decrease. The necessity for this equipment and the applicability of these regulations given new technologies such as enhanced vision (EV) and synthetic vision (SV) should be reevaluated.

*lynda.j.kramer@nasa.gov; phone 1757 864-8146; fax 1757 864-7793 
A vivid demonstration of the current complexity (and cost) to meet "weather and visibility-independent" capability is to look at the present National Air Space (NAS) infrastructure. As of January 2008, there were 1,229 ILS instrument approach procedures (IAPs) to Category I minima (no lower than $200 \mathrm{ft}$ decision height, $2400 \mathrm{ft}$ visibility) available throughout the United States, but only 143 Category II (no lower than $100 \mathrm{ft}$ decision height, $1200 \mathrm{ft}$ visibility) and 111 Category III (a decision height lower than $100 \mathrm{ft}$, or no decision height, or a runway visual range (RVR) less than 1200 ft) IAPs ${ }^{2}$ using 1,367 Instrument Landing Systems (ILS) in the NAS. ${ }^{3}$ In addition to precision guidance ILS, approach lighting systems of increasing complexity are required by regulation as landing visibility minima decrease. Typical for Category I precision approaches is the MALSR (Medium Intensity Approach Lighting System with Runway Alignment Indicator Lights) approach lighting system (ALS). Currently, there are approximately 900 MALSR in the NAS. ${ }^{4}$ For Category II/III landing minima, the ALSF-2 (High Intensity Approach Lighting System with Sequenced Flashing Lights) ALS is installed to provide the visual information for runway alignment, height perception, roll guidance, and horizontal references. In Figure 1, a comparative view of different ALSs is shown, including a typical "VFR" (Visual Flight Rules) configuration (which would not support an instrument approach procedure under the current regulations). By FAA estimates $^{5}$, the facilities and equipment (F\&E) costs for a single MALSR installation was nearly $\$ 1 \mathrm{M}$, representing almost $50 \%$ of the total F\&E costs for a Category I capability. The ALSF-2 costs are nearly 3 times this amount and they comprise over $70 \%$ of the total F\&E costs for a Category II/III capability. The 20 year life cycle costs for the MALSR were estimated at $\$ 1.7 \mathrm{M}$, climbing to $\$ 5.4 \mathrm{M}$ for a ALSF-2 light system with a Category III landing minima.
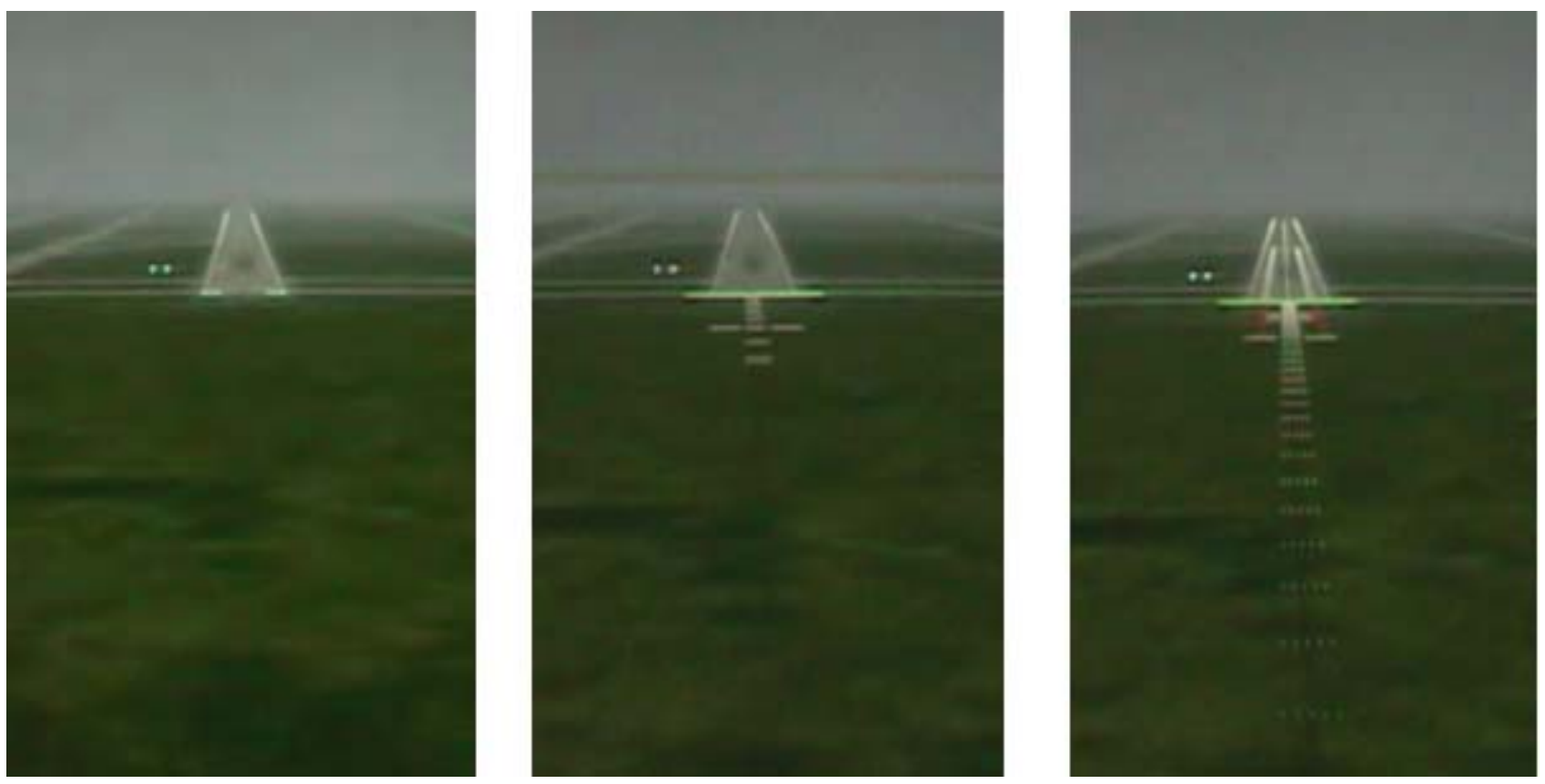

Figure 1. Approach Lighting System Configurations - VFR (left), MALSR (center), and ALSF-2 (right)

To meet the operational goals of NextGen, all-weather, Category III-type capability is desired for all runways. This goal is economically unlikely, however, if these infrastructure requirements remain in place. Technology innovation may provide an avenue by which the safety and performance provided by this infrastructure can be economically replaced. Synthetic Vision and Enhanced Vision capability may offer crew/vehicle interface technologies that help achieve this goal and the realization of EVO in the next generation NAS by obviating the requirement for elaborate ALSs and other infrastructure needs to support lower landing minima.

\section{BACKGROUND}

Synthetic vision is a computer-generated image of the external scene topography that is generated from aircraft attitude, high-precision navigation, and data of the terrain, obstacles, cultural features, and other required flight information. A synthetic vision system (SVS) enhances this basic functionality with real-time integrity to ensure the validity of the databases, perform obstacle detection and independent navigation accuracy verification, and provide traffic surveillance. Under NASA's Aviation Safety Program/Synthetic Vision Project (1999-2006), NASA and its industry partners 
developed and deployed SVS technologies for commercial and business aircraft which were shown to provide significant improvements in terrain awareness and reductions for the potential of Controlled-Flight-Into-Terrain incidents/accidents compared to current generation cockpit technologies. ${ }^{6-11}$

It has been hypothesized that the use of SV technologies on head-up and head-down displays can provide precision approach, landing, and taxi guidance for "all weather" capability to all runways without requiring extensive approach lighting systems, ground-based precision guidance systems such as the ILS, or other airport infrastructure. These technologies may provide "equivalent vision" capabilities which would obviate the need for airport lighting and other infrastructure to support the flight crews' need to visually acquire runways and taxiways using normal vision.

An experiment was conducted to evaluate the effects of the presence or absence of Synthetic Vision, the location of this information during an instrument approach (i.e., on a Head-Up or Head-Down Primary Flight Display), and the type of airport lighting information on landing minima. The "operational considerations" evaluated under this effort included reduced visibility, decision altitudes, and airport approach lighting systems, for SVS-equipped and non-equipped aircraft. Another key element of the testing entailed investigating the pilot's awareness and reaction to non-normal events (i.e., failure conditions) that were unexpectedly introduced into the experiment. These non-normals are critical determinants in the underlying safety of all-weather operations.

The main objectives of this experiment were to:

1) Evaluate SVS and SVS-related technologies to develop operational concepts for all-weather approach and landing; and,

2) Provide quantitative and qualitative information that could be used to develop criteria for all-weather approach and landing technologies such as synthetic vision.

The qualitative data and experimental hypotheses, focusing on the Objective 1 noted above, have been reported in detail in Reference 12.

In this paper, the experimental data are evaluated using proposed performance-based approach and landing standards in addressing Objective 2 noted above. The results are presented within the context of emerging operational concepts for EVO. In addition, the effects of reduced visibility, decision altitudes, and airport equipage requirements on SVSequipped and non-equipped aircraft, the role of display location (Head-Down Display (HDD) vs. Head-Up Display (HUD)) in landing operations and the pilot decision-making process are also investigated.

\section{EXPERIMENT}

In the following section, a brief review of the experiment is given as background for the analyses that follow in Section 4. Additional details for the experiment are contained in Reference 12.

\subsection{Simulation}

The experiment was conducted in the Integration Flight Deck (IFD) full-mission simulator facility (see Fig. 2) at NASA Langley Research Center (LaRC). A collimated out-the-window (OTW) scene provided 200 degrees horizontal by 40 degrees vertical field-of-view at 26 pixels per degree.

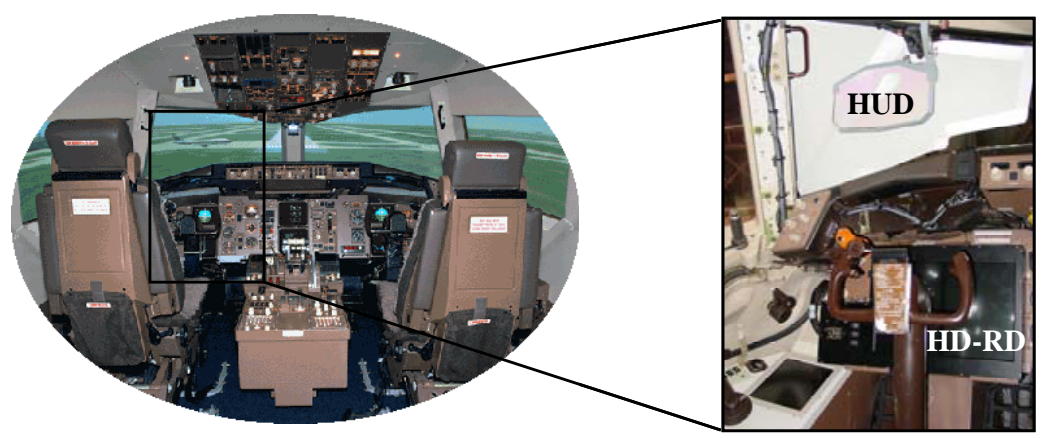

Figure 2. Integration Flight Deck Simulation Facility with HUD and Head-Down Research Display (HD-RD). 
The evaluation pilot (EP) occupied the left seat, as the Pilot Flying (PF) for this experiment. The left seat included an overhead HUD projection unit and a head-down research display (RD) (see Fig. 2). Twenty-three pilots, representing seven airlines and the Federal Aviation Administration (FAA) Flight Standards and Transport Aircraft Certification Branches, participated in the experiment.

\subsection{Displays}

The HUD subtended approximately $26^{\circ}$ horizontal by $21^{\circ}$ vertical field of view (FOV). The input consisted of a video mix of symbology and computer-generated scene imagery. The symbology included "haloing" to ensure that the symbology was highlighted against the scene imagery background. HUD brightness, contrast and "declutter" controls were provided. The SV imagery, when displayed, was drawn conformally.

A head-down research display was installed over the normal instruments on the left hand side of the IFD cockpit (see Fig 22). Two Size D (6.4 x 6.4 inch) primary flight display (PFD) and navigation displays (ND) were drawn.

\subsection{Synthetic Vision Database}

A synthetic vision database was created from a 0.33 arc-sec ( 10 meter post-spacing) Digital Elevation Model (DEM) of a $53 \times 57 \mathrm{~nm}$ area centered around the Dallas- Ft. Worth International Airport (FAA identifier: KDFW). The DEM was draped with elevation-based generic imagery. The airport was represented by three-dimension models of the runway, taxiways, and terminal buildings which were extracted from aerial photography of approximately 1 foot resolution.

\subsection{Symbology}

\subsubsection{HUD Symbology}

The HUD stroke symbology is shown in Figure 3. Glideslope and localizer raw data "path deviation" indicators were provided in addition to Flight Path Marker (FPM) and guidance information. The pitch-roll guidance cue ("ball") used modified pursuit guidance ${ }^{13}$ along the desired path centerline, 5.5 seconds ahead of ownship. Horizontal and vertical position of the ball reflects the track and flight path angles to fly to the center of the desired path. A glideslope reference line was drawn at the DFW Runway 18R Instrument Landing System (ILS) descent angle of 3.0 degrees. Also, a runway outline symbol was drawn using the threshold coordinates of the DFW $18 \mathrm{R} / 36 \mathrm{~L}$ runway based on the simulated aircraft navigation solution to conformally position the symbol. The runway outline was drawn using an $8000 \mathrm{ft} \times 200 \mathrm{ft}$ runway. Finally, radar altitude was shown digitally underneath the FPM when below $500 \mathrm{ft}$ above ground level (AGL).

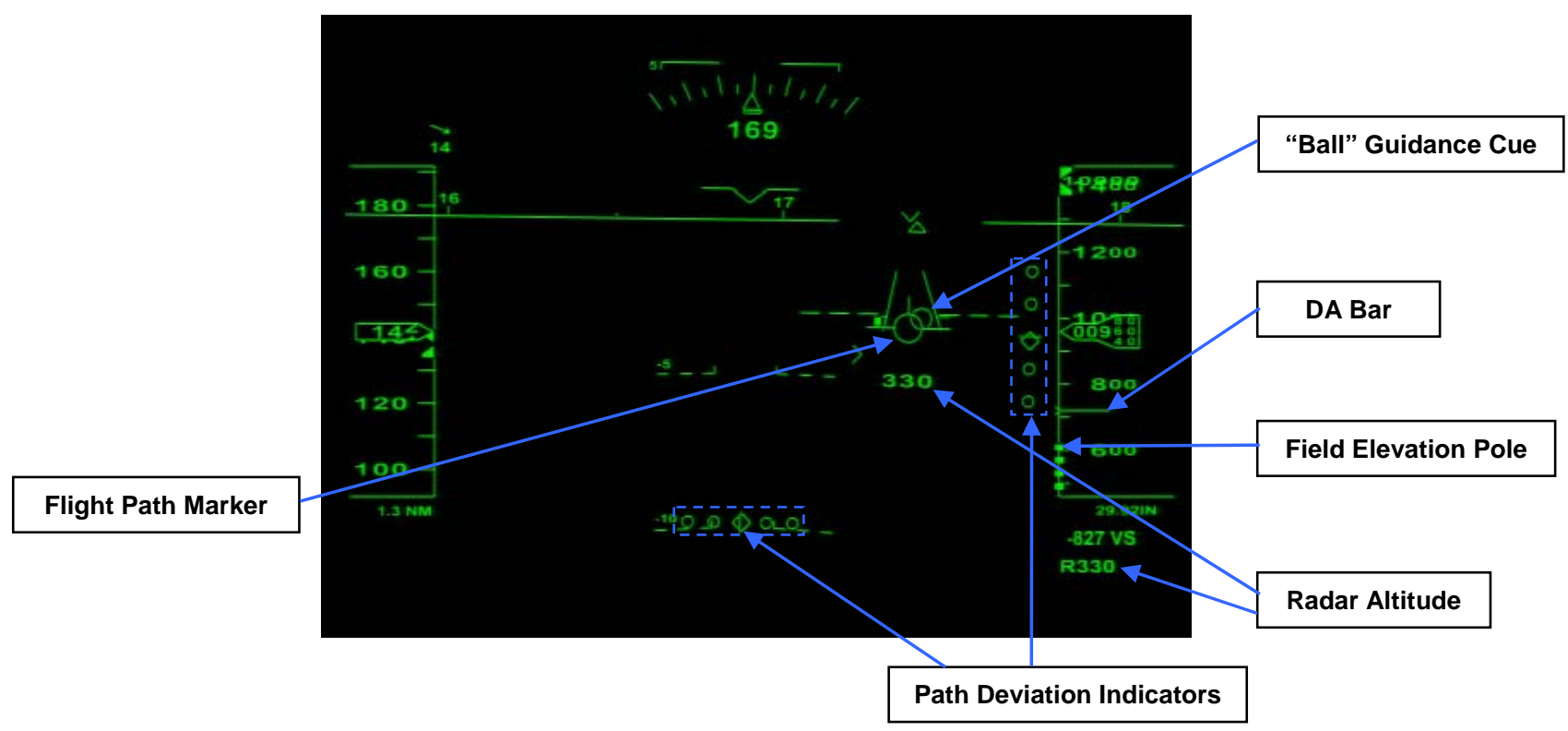

Figure 3. HUD Symbology 


\subsubsection{PFD Symbology}

The PFD symbology was essentially the same as the HUD. See Reference 12 for details.

\subsection{Display Concepts}

Four display concepts (baseline and SV, either head-up or head-down) were evaluated by the evaluation pilots while flying approaches to DFW Runway 18R. The head-down navigation display format was invariant.

\subsubsection{Head-Up Display Concepts}

Two HUD display concepts were tested, differing from each other only in the type of raster background (SV or none) presented. Standard HUD symbology enhanced with a runway outline was employed in both HUD concepts. In Figure 4, the two HUD Concepts are shown - the Baseline HUD (left) and the SV HUD (right). During the HUD experimental runs, the "baseline" PFD was displayed (PFD format shown on the left side of Figure 5).
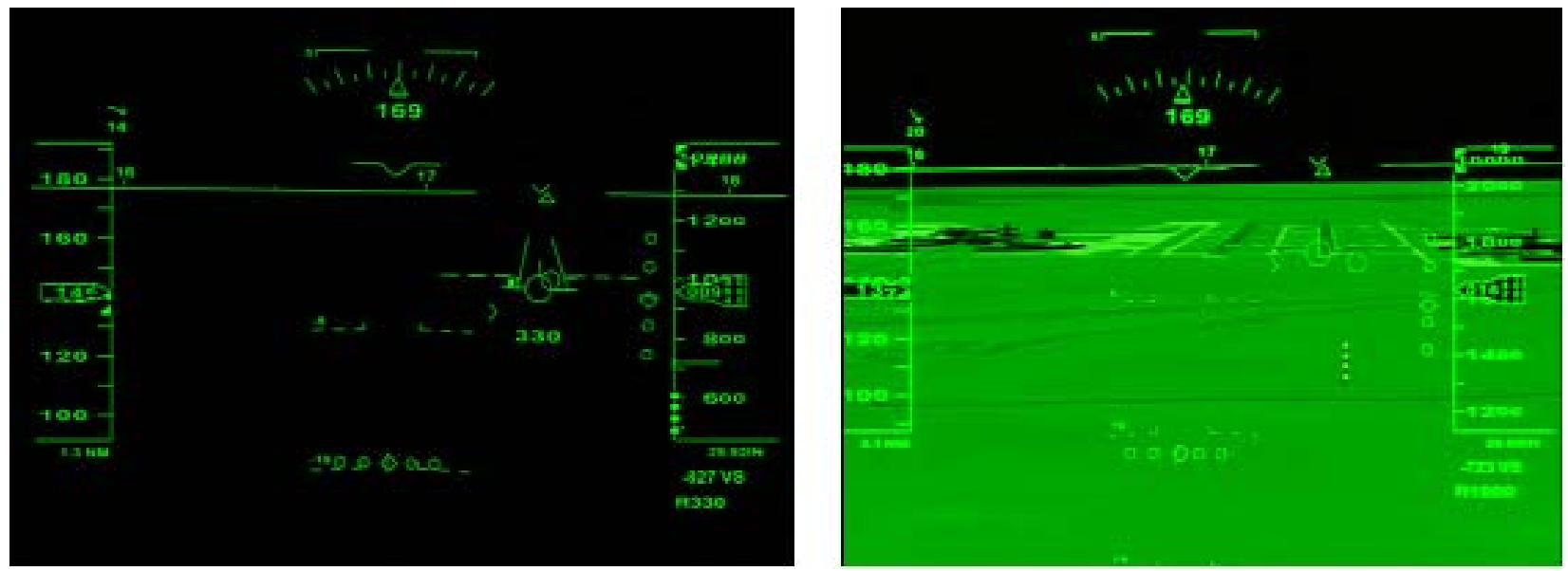

Figure 4. Head-Up Display (HUD) Formats - Baseline-HUD (left) and SV-HUD (right).

\subsubsection{Head-Down Display Concepts}

Two PFD display concepts were tested, differing from each other only in the type of background (standard sky/ground or SV) presented with the flight symbology. Figure 5 presents the PFD concepts used for the Baseline HDD (left) and the Synthetic Vision HDD (right) configurations. For the HDD evaluations, the HUD was stowed to preclude blocking or distortion of the pilot's forward view of the outside world.
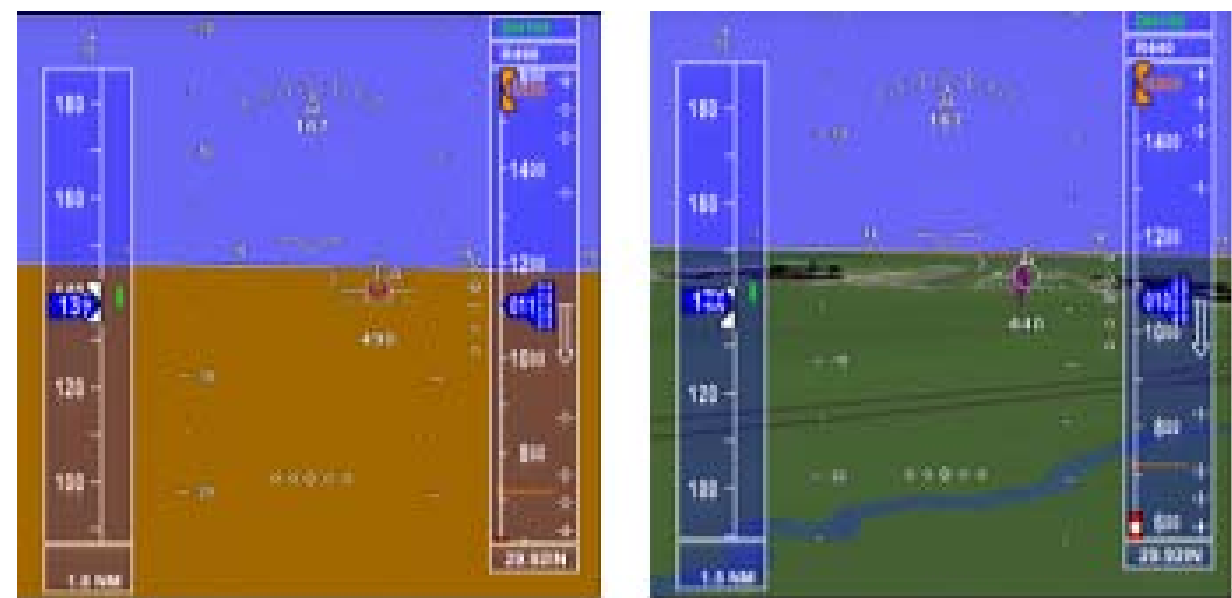

Figure 5. Primary Flight Display (PFD) Formats - Baseline-HDD PFD (left) and SV-HDD PFD (right). 


\subsection{Approach Lighting System Configurations}

Three different ALS configurations were used for this experiment as shown in Figure 1. The first ALS configuration (hereinafter referred to as the VFR ALS) was representative of lights typically found at a VFR runway and included Runway End Identification Lights (REIL), precision approach path indicator lights (PAPI), partial threshold lights, and medium intensity runway lights (MIRL). The second ALS configuration (hereinafter referred to as the MALSR ALS) was representative of a Category I/Type I operations runway and included MALSR (medium intensity approach lighting system; runway alignment indicator lights), REIL, PAPI, full threshold lights, and MIRL. The third ALS configuration (hereinafter referred to as the ALSF-2 ALS) was representative of a standard Category II/Type II operations runway and included ALSF-2 (high intensity approach lighting system with sequenced flashing lights), touchdown zone and centerline lighting, REIL, PAPI, full threshold lights, and high intensity runway lights (HIRL).

\subsection{Evaluation Task}

The evaluation task was a straight-in Global Positioning System (GPS) approach with a 3 degree descent angle to Runway 18R at DFW airport. For each run, the approach started 5 nautical miles (nm) from the runway threshold and the aircraft was placed one dot left or right of the course centerline, and one dot high or low of the course glidepath. The weather consisted of altitude-based cross winds (wind direction and intensity was dependent on altitude), light turbulence (root-mean-square (rms) of $2 \mathrm{ft} / \mathrm{sec}$ ), and varying visibility levels ( 3 miles, $2400 \mathrm{ft}, 1800 \mathrm{ft}$, or $1200 \mathrm{ft}$ RVR). The evaluation pilot hand-flew the approach from the left seat with auto-throttles engaged at a speed of 138 knots. The run was terminated at full-stop or upon go-around initiation. The aircraft was configured to land prior to each run (landing gear down and flaps 30 degrees). There was no other aircraft or ATC involvement in the task.

The evaluation pilots were instructed to fly the aircraft as if there were passengers aboard, fly the center of the approach path, and land as close as possible to the centerline and touchdown zone (1000 feet from the runway threshold). They were also instructed to initiate a go-around if the landing was not safe or if there were any safety concerns.

Each approach used a decision altitude (DA) of either $200 \mathrm{ft}$ or $100 \mathrm{ft}$. The DA was briefed before each run.

An automatic aural call-out was included in the simulation to "assist" in altitude awareness. A "500 feet" call-out was made at $500 \mathrm{ft}$ above field level (AFL). An "Approaching Minimums" call-out was made at $100 \mathrm{ft}$ above the DA for the run (100 or $200 \mathrm{ft}$ AFL). Finally, a "Minimums" call-out was made at the pre-set DA.

The EPs were instructed to verbally denote and acknowledge their recognition of the required runway visual references in accordance with existing FAR 91.175 regulations. The pilot was instructed to call "Lights" when the approach lighting system became visible and to call "Landing" when the required landing visual references (as specified in FAR Part 91.175c) became identifiable. The procedures were as follows:

- For approaches with a DA of $200 \mathrm{ft}$, the pilot had to visually acquire the approach lighting system or the runway landing references no later than the "minimums" call-out to continue the approach below $200 \mathrm{ft}$ AFL. If the approach continued, the pilot continued to landing only if the required landing visual references became identifiable before $100 \mathrm{ft}$ AFL, else a call of "go-around" was required.

- For approaches with a DA of $100 \mathrm{ft}$, there was an automatic call-out of "Approaching Minimums" at $200 \mathrm{ft}$ AFL and an automatic call-out of "Minimums" at $100 \mathrm{ft}$ AFL. If the "Landing" call was made before $100 \mathrm{ft}$ AFL, the approach could continue to landing, else a call of "go-around" was required.

\subsection{Experiment Matrix}

Nominally, ten training runs and fifty-three experimental runs were completed by each EP.

The primary experiment matrix consisted of combinations (but not a full-factorial) of Display Concept (Baseline-HDD, SV-HDD, Baseline-HUD, or SV-HUD), ALS (VFR, MALSR, or ALSF-2), runway visibility range (1200 ft, $1800 \mathrm{ft}$, $2400 \mathrm{ft}$, or 3 statute miles), and DA (100 or $200 \mathrm{ft}$ ) as shown in Table 1. Two additional runs (one at $2400 \mathrm{ft}$ RVR/ 200 $\mathrm{ft}$ DA/ MALSR ALS and one at 3 mile RVR/ VFR ALS) using the Baseline HDD concept but without flight directortype guidance were also completed by each EP.

A significant component of the test, in addition to the nominal runs, was the investigation of the ability of the EP to recognize and properly handle non-normal events. Seven non-normal runs were flown by each EP. The non-normal runs were four database integrity monitoring scenarios, two altimetry failure scenarios, and one SV obstacle placement error scenario. The non-normal results and their implications of safety are discussed in Reference 12. 
Table 1: Primary Experiment Matrix

\begin{tabular}{|lc|c|c|c|}
\hline Visibility & Decision Altitude & VFR $\boldsymbol{A L S}$ & MALSR & ALSF-2 \\
\hline \hline $1200 \mathrm{ft} R V R$ & $100 \mathrm{ft}$ & $\sqrt{ }$ & $\sqrt{ }$ & $\sqrt{ }$ \\
\cline { 2 - 5 } & $200 \mathrm{ft}$ & & $\sqrt{ }$ & \\
\hline $1800 \mathrm{ft} R V R$ & $100 \mathrm{ft}$ & & $\sqrt{ }$ & \\
\cline { 2 - 5 } & $200 \mathrm{ft}$ & & $\sqrt{ }$ & $\sqrt{ }$ \\
\hline & $100 \mathrm{ft}$ & $\sqrt{ }$ & & \\
\hline 3 statute miles & $200 \mathrm{ft}$ & & & \\
\hline
\end{tabular}

Note: the checked cases were evaluated using each of the four display concepts: Baseline PFD, SV PFD, Baseline HUD, and SV HUD

\subsection{Test Conduct}

The subjects were given a 1-hour briefing, explaining the HUD and PFD concepts, pilot procedures, and the evaluation tasks. After the briefing, a 1-hour training session in the IFD was conducted to familiarize the subjects with the aircraft handling qualities, display symbologies, pilot procedures, and controls. The 'rare-event' (or non-normal) scenarios were not discussed, although the pilot's responsibility for maintaining safe operations at all times was stressed.

\section{RESULTS}

In the following section, the experimental data analyses are presented. Existing performance-based approach and landing criteria associated with related technology are assessed for applicability as criteria for emerging technologies to meet all-weather approach and landing operations. These analyses additionally address the effects of reduced visibility, decision altitudes, and airport equipage with SVS-equipped and non-equipped aircraft and the role of display location (HDD vs HUD) in approach and landing operations.

For the objective performance measures, analysis of variance (ANOVA) was conducted for the factors of display location (HDD, HUD), display information content (Baseline, SV), ALS (VFR, MALSR, ALSF-2), RVR (1200, 1800, $2400)$, and DA $(100,200)$ where appropriate. When necessary, Student-Newman-Keuls (SNK) post-hoc tests with $\alpha$ set at 0.05 were performed.

\subsection{Experimental Measures}

During each run, aircraft state data (i.e., path error, pilot control inputs, sink rate at touchdown and touchdown location) were recorded for later analysis. After each run, pilots completed a run questionnaire consisting of the NASA Task Load Index (TLX) workload rating, ${ }^{14}$ Situation Awareness Rating Technique (SART) ${ }^{14}$ and six Likert-type (5-point) questions specific to different constructs of making a stabilized and safe approach. ${ }^{15}$ After data collection was completed, pilots were administered the Situation Awareness - Subjective Workload Dominance (SA-SWORD) ${ }^{16}$ and Subjective Workload Dominance (SWORD) ${ }^{14}$ tests for the display concept (Baseline-HDD, SV-HDD, Baseline-HUD, SV-HUD) comparisons. The pilots also completed a post-test questionnaire designed to elicit comments on the display concepts with the various approach lighting systems, the visual transition strategy employed by the pilot with the different display concepts, the pilot procedures, and the fidelity of the simulator.

\subsection{Subjective Results}

The subjective data analyses were previously reported ${ }^{12}$ and are summarized below:

- Post-test paired comparison tests for situation awareness (SA) and pilot workload showed that the SV-HUD provided the highest SA and lowest workload for any of the tested display concepts. The lowest SA and highest workload was associated with the Baseline-HDD concept. The pilot workload associated with the SVHDD and the Baseline-HUD was rated by the pilots as being equal but the SA provided by the SV-PFD was rated significantly better than the Baseline-HUD. 
- Post-run subjective ratings included the effects of RVR and ALS, as well as the display concepts:

- The TLX data showed that the addition of SV on the HUD provided significant pilot workload reduction, but it did not significantly improve pilot workload when added to the HDD. The workload in flying the $1200 \mathrm{ft}$ RVR approaches was significantly higher than the $2400 \mathrm{ft}$ and $1800 \mathrm{ft}$ RVR approaches (which were not significantly different from each other). The type of ALS employed did not affect pilot workload.

- The SART data showed that the addition of SV on both the HUD and HDD provided significant SA improvements, and the HUD provided significantly improved SA over the HDD. SA while flying the 1200 $\mathrm{ft}$ RVR approaches was significantly lower than the $2400 \mathrm{ft}$ and $1800 \mathrm{ft}$ RVR approaches (which were not significantly different from each other). The type of ALS employed did not affect SA.

- Post-run ratings indicated that the pilots felt that their lateral alignment and roll guidance were significantly improved when using SV compared to the baseline condition and when using the HUD versus the HDD, but no significant differences were found among the approach lighting systems or visibility conditions. In addition, there were no operationally significant differences for the approach lighting systems or visibility conditions in pilot post-run ratings of their ability to find the runway and touchdown zone references or to identify the necessary visual references when transitioning from instrument to visual flight to safely execute the landing. In fact, even with RVR as low as $1200 \mathrm{ft}$, the pilot's felt, on average, that they could safely complete the approach and landing with the display configurations and lighting conditions tested.

These data showed that the ALS had no effect on workload or situation awareness during low visibility approaches. However, the one area where the ALS did have a profound effect was on the ability to continue the approach below the DA; that is, the pilot's ability to see the required landing references. As shown in Figure 6, the percentage of approaches flown to touchdown reduced as the RVR decreased, to the extent that an approach flown on a VFR ALS in $1200 \mathrm{ft}$ RVR had only a 50-50 chance of concluding to a touchdown, even when the pilots flew to a $100 \mathrm{ft}$ DA. For this same condition, with either a MALSR or ALSF-2 ALS, the data shows a significant improvement in completed approaches (now $85-88 \%$ ). With a $100 \mathrm{ft}$ decision height, the number of completed approaches is independent of MALSR and ALSF-2. If a $100 \mathrm{ft}$ reduction in DA (from $200 \mathrm{ft}$ to $100 \mathrm{ft}$ ) is possible, the data shows a $20 \%$ improvement in the percentage of completed landings when using the MALSR, in 1800 and $1200 \mathrm{ft}$ RVR.

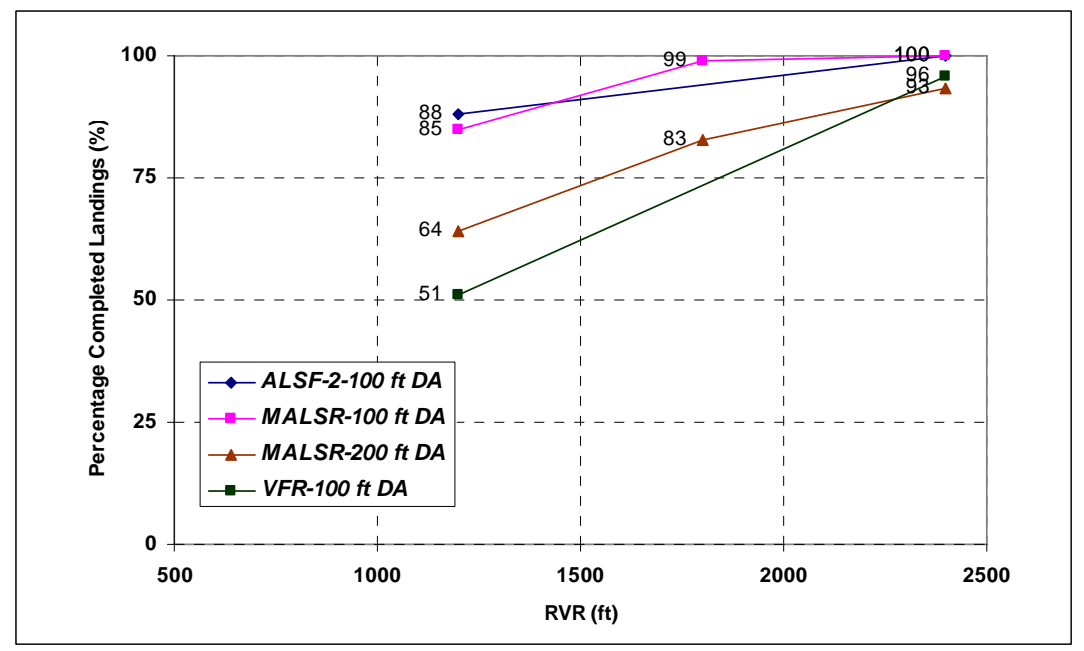

Figure 6. Percentage of Completed Landings by RVR and ALS

\subsection{Objective Approach Performance}

Approach performance was first assessed using rms localizer and rms glide slope deviation (in dots); maximum bank angle (deg); and rms sink rate (feet per minute, fpm). These parameters correspond intuitively to the establishment and maintenance of a stabilized approach to landing - an important safety measure ${ }^{17,20}$. 
The approach data were analyzed from $900 \mathrm{ft}$ to DA (either 200 or $100 \mathrm{ft}$ ). The $900 \mathrm{ft}$ altitude was arbitrarily applied to reduce the potential bias introduced by the experiment set-up, in which all approaches were initiated with an intentional lateral and vertical offset. Guidance cueing would be expected to lead the aircraft to the path intercept at $900 \mathrm{ft}$ AGL.

\subsubsection{Path Deviation}

Localizer angular deviation: The main factor of location $(F(1,56)=14.43, \mathrm{p}<0.001)$ and the second order interactions of RVR $x$ DA $(\mathrm{F}(2,591)=9.53, \mathrm{p}<0.001)$, location $x$ RVR $(\mathrm{F}(2,591)=6.61, \mathrm{p}=0.001)$, lights $\mathrm{x}$ location $(\mathrm{F}(2,591)=6.59$, $\mathrm{p}=0.001)$, lights $\mathrm{x}$ content $(\mathrm{F}(2,591)=3.08, \mathrm{p}=0.047)$, DA $\mathrm{x}$ location $(\mathrm{F}(1,591)=4.40, \mathrm{p}=0.036)$, and location $\mathrm{x}$ content $(\mathrm{F}(1,591)=4.28, \mathrm{p}=0.039)$ were significant for rms localizer deviation. The other main factors (content, RVR, ALS, and DA) and remaining second order interactions were not significant $(p>0.05)$ for this measure. Pilots had less rms localizer deviation when flying: 1 ) the HUD (mean $=0.060$ dots and standard deviation, $\sigma=0.036$ ) versus the HDD (mean $=0.068$ dots and $\sigma=0.029$ ). The interaction effects in this case were not operationally significant and are not reported.

Glide slope angular deviation: The main factors of DA $(F(1,24)=59.20, p<0.001)$ and location $(F(1,47)=15.64$, $\mathrm{p}<0.001)$ and the second order interaction of DA $x$ location $(F(1,591)=3.89, p=0.049)$ were significant for rms glide slope deviation. The other main factors (content, RVR, and ALS) and second order interactions were not significant ( $>0.05$ ) for this measure. Pilots flew more precise glide path: 1) to a $200 \mathrm{ft} \mathrm{DA}$ (mean=0.262 dots and $\sigma=0.147$ ) than to a $100 \mathrm{ft}$ DA (mean $=0.338$ dots and $\sigma=0.177$ ) and 2) with the HUD (mean $=0.270$ dots and $\sigma=0.141$ ) compared to the HDD (mean $=0.366$ dots and $\sigma=0.188$ ).

\subsection{2. $\quad$ Roll Stability}

The main factors of location $(F(1,46)=16.94, p<0.001)$ and $\operatorname{RVR}(F(2,83)=3.77, p=0.027)$ and the second order interaction of location $\mathrm{x}$ content $(\mathrm{F}(1,591)=4.65, \mathrm{p}=0.031)$ were significant for maximum bank angle. The other main factors and all the second order interactions were not significant $(\mathrm{p}>0.05)$ for this measure. Greater roll stability (less maximum bank angle) was achieved when flying the HUD (mean=5.1 deg) vs. the HDD (mean=6.0 deg). Post-hoc tests (SNK using $\alpha=0.05$ ) showed three unique subsets for bank angle with the 3 RVR values: 1) $2400 \mathrm{ft}$ (mean=5.2 deg), 2) $1800 \mathrm{ft}$ (mean=5.6 deg) and 3) $1200 \mathrm{ft}$ (mean=5.9 deg) - these differences are operationally inconsequential. Visual inspection of the data revealed that all runs were flown with bank angles of less than 30 degrees from $1000 \mathrm{ft}$ AGL to touchdown which is what is expected from professional pilots during a stabilized approach. ${ }^{17}$

\subsubsection{Descent Stability}

The main factor of location $(\mathrm{F}(1,31)=31.96, \mathrm{p}<0.001)$ and the second order interactions of $\mathrm{DA} \times \mathrm{x}$ location $(\mathrm{F}(1,591)=4.67, \mathrm{p}=0.031), \mathrm{DA} \times \mathrm{x}$ content $(\mathrm{F}(1,591)=4.67, \mathrm{p}=0.031)$ and location $\mathrm{x}$ content $(\mathrm{F}(1,591)=9.53, \mathrm{p}=0.002)$ were significant for rms sink rate deviation. None of the other main factors or second order interactions were significant $(\mathrm{p}>0.05)$ for this measure. Greater descent stability (lower rms sink rate deviation from nominal value of $723 \mathrm{fpm}$ ) was achieved when flying the HUD (mean=119 fpm and $\sigma=38$ ) versus the HDD (mean=165 fpm and $\sigma=58$ ). The interaction effects in this case were not operationally significant and are not reported.

\subsection{Objective Approach Standards Application}

Existing performance-based approach standards were also applied in the objective data analysis. These standards were drawn from numerous sources pertaining to the general concept of low-visibility approach and landings. However, none of these were written specifically as quantitative performance standards for Synthetic and Enhanced System operations. The analyses that follow examine their applicability for this purpose. (The notable exception is that the Enhanced Flight Vision Systems Advisory Circular (AC No. 90-EFVS (Draft)), states that "the use of EFVS must achieve the same degree of accuracy and flight technical error as a Category II integrated instrument landing system approach.”)

A synopsis of these existing quantitative performance requirements for glideslope and localizer tracking from FAA and Joint Aviation Regulations (JAR) are shown in Table II. In Reference 19, glideslope and localizer performance requirements are expressed in microamps, with 150 microamps equal to full scale deflection on the ILS. In Table II, glideslope and localizer deviations are expressed in dots deflection by assuming $+/-2$ dots full scale deflection corresponds to $+/-150$ microamps deviation from on-course.

This synopsis emphasizes "performance" parameters of interest that are relevant to this experiment and does not include many important regulation facets and nuances for the sake of brevity. Of particular note, airspeed, sink rate, and bank 
angle control are typically evaluated but are not reported herein since autothrottles were engaged for all runs and sink rate and bank angle control differences among the main factors were found to be operationally inconsequential as described in Section 4.3 above.

The existing quantitative performance standards emphasize the maximum glideslope and localizer deviations, instead of rms deviation as shown above. The approach data were analyzed only for those approaches that were flown to touchdown.

The percentage of approaches which meet the four criteria are shown, broken down by display configuration in Table III. (The variables, ALS and RVR, were not considered to be important influences in these results and are not shown.) The influence of DA is also shown in Table III, where, if the criteria window included "DA," then the analysis used a corresponding altitude window down to $200 \mathrm{ft}$ or to $100 \mathrm{ft}$ as appropriate.

Table II: Quantitative Approach Performance Standards

\begin{tabular}{|l|l|l|}
\hline & Localizer Tracking & Glideslope Tracking \\
\hline $\begin{array}{l}\text { Practical Test Standard } \\
\text { (PTS) } \\
\text { Reference 18 }\end{array}$ & $\begin{array}{l}<3 / 4 \text { Full Scale Deflection (i.e., 1.5 } \\
\text { dots), Between Final Approach Fix and } \\
\text { Decision Height }\end{array}$ & $\begin{array}{l}<3 / 4 \text { Full Scale Deflection, (i.e., 1.5 dots) } \\
\text { Between Final Approach Fix and Decision } \\
\text { Height }\end{array}$ \\
\hline $\begin{array}{l}\text { AC 120-29, } \\
\text { Appendix 2, Paragraph 6.2.1. } \\
\text { Reference 21 }\end{array}$ & $\begin{array}{l}<1 / 3 \text { (i.e., 2/3 dots) Full Scale } \\
\text { Deflection from 1000' Height Above } \\
\text { Touchdown (HAT) to 200' HAT }\end{array}$ & $\begin{array}{l}<1 / 2 \text { Full Scale (i.e., 1 dot) Deflection from } \\
700 \text { ' HAT to 200' HAT }\end{array}$ \\
\hline $\begin{array}{l}\text { “Cat 2, Successful Approach” } \\
\text { FAR Part 91, Appendix A, } \\
\text { Section 3, Subsection e2 }\end{array}$ & $\begin{array}{l}\text { At } 100 \mathrm{ft} \text { DH, cockpit is within and } \\
\text { tracking so as to remain within, the } \\
\text { lateral confines of the runway } \\
\text { extended. }\end{array}$ & $\begin{array}{l}\text { Deviation from glideslope after leaving the } \\
\text { outer marker does not exceed 50\% Full } \\
\text { Scale Deflection (i.e., 1 dot down to 100 ft } \\
\text { DH) }\end{array}$ \\
\hline $\begin{array}{l}\text { Joint Aviation Regulations }- \\
\text { All Weather Operations } \\
\text { AMC AWO 231 } \\
\text { Reference 22 }\end{array}$ & $\begin{array}{l}\text { No more than 5\% of approaches with } \\
>1 / 3 \text { dot between 300 ft and 100 ft } \\
\text { HAT }\end{array}$ & $\begin{array}{l}\text { No more than 5\% of approaches with }>1 \\
\text { dot between 300 ft and 100 ft HAT }\end{array}$ \\
\hline
\end{tabular}

There were 200 approaches flown to touchdown using the Baseline-HDD, 185 for the SV-HDD, 205 for the BaselineHUD, and 200 for the SV-HUD, of which 145, 135, 147, and 142 approaches, respectively, were flown using a $100 \mathrm{ft}$ DA. Note that the data in Table III for the JAR-AWO just used exceedance data (i.e., approaches where $>1 / 3$ dot for localizer or $>1$ dot for glideslope were not found, between $300 \mathrm{ft}$ and $100 \mathrm{ft}$ AFL). Statistical analysis to ensure a $95 \%$ bound as per JAR-AWO have not yet been performed. Therefore, these results may be considered optimistic against this criterion.

Table III: Percentage Approaches Successfully Meeting Approach Performance Standards

\begin{tabular}{|c|c|c|c|c|c|c|}
\hline & & & \multicolumn{2}{|c|}{ Localizer } & \multicolumn{2}{|c|}{ Glideslope } \\
\hline & & & $H D D$ & $H U D$ & $H D D$ & HUD \\
\hline \multirow[t]{4}{*}{ PTS } & \multirow[t]{2}{*}{$200 \mathrm{ft} D A$} & Baseline & $100 \%$ & $98 \%$ & $95 \%$ & $98 \%$ \\
\hline & & $S V$ & $100 \%$ & $100 \%$ & $90 \%$ & $98 \%$ \\
\hline & \multirow[t]{2}{*}{$100 \mathrm{ft} D A$} & Baseline & $100 \%$ & $100 \%$ & $72 \%$ & $90 \%$ \\
\hline & & $S V$ & $100 \%$ & $100 \%$ & $73 \%$ & $93 \%$ \\
\hline \multirow[t]{2}{*}{ AC 120-29 } & \multirow[t]{2}{*}{$200 \& 100$} & Baseline & $100 \%$ & $99 \%$ & $83 \%$ & $95 \%$ \\
\hline & & $S V$ & $100 \%$ & $100 \%$ & $85 \%$ & $97 \%$ \\
\hline FAR 91 & $100 \mathrm{ft} D A$ & Baseline & $100 \%$ & $100 \%$ & $50 \%$ & $79 \%$ \\
\hline
\end{tabular}




\begin{tabular}{|c|c|c|c|c|c|c|}
\hline & & & & & \\
\hline & & $S V$ & $100 \%$ & $100 \%$ & $62 \%$ & $82 \%$ \\
\hline \multirow[t]{4}{*}{ JAR-AWO } & \multirow[t]{2}{*}{$200 \mathrm{ft} D A$} & Baseline & $100 \%$ & $100 \%$ & $44 \%$ & $69 \%$ \\
\hline & & SV & $98 \%$ & $100 \%$ & $42 \%$ & $67 \%$ \\
\hline & \multirow[t]{2}{*}{$100 \mathrm{ft} D A$} & Baseline & $99 \%$ & $99 \%$ & $50 \%$ & $79 \%$ \\
\hline & & $S V$ & $99 \%$ & $99 \%$ & $62 \%$ & $82 \%$ \\
\hline
\end{tabular}

The data of Table III shows that localizer tracking is never a problem, irrespective of the criteria. At most, only 2 exceedances were encountered for any of the criteria. Glideslope tracking, on the other hand, was a much more stringent discriminator and revealed several characteristics which must be considered in using these criteria as quantitative criteria for approach and landing operations:

- Glideslope tracking was always superior using the HUD compared to the HDD. This result is likely due to the conformal nature of the HUD (the HDD was a minified display) and its head-up location, as discussed in the following.

- The presence or absence of SV doesn't appear to dramatically influence the success or failure for glideslope tracking although statistical significance has not yet been determined. For the HDD concept, the presence of SV does seem to improve acceptable performance rate for approaches going to $100 \mathrm{ft}$ DA (i.e., see FAR-91, comparing SV/Baseline above). The presence of SV may be improving the pilot's ability to interpret the guidance in the regime where the glideslope sensitivity is increasing dramatically. Otherwise, SV should not be a significant influence; the more important determinants for glidepath tracking should be the quality of the guidance and the pilot's capability and ability to track this information.

- Down to $200 \mathrm{ft} \mathrm{HAT}$, the pilots could maintain glidepath within 1.5 dots between $90-95 \%$ of the time using the HDD and 98\% with the HUD (i.e., the PTS Standard). When the tighter AC120-29 standard of 1.0 dot is used, there is only a minimal drop in HUD performance acceptability (down to 96\%) but acceptable HDD performance is down to $84 \%$. This performance drop for the HDD condition is likely the result of the pilot going "head-out" during this critical time to search for the required visual references while flying head-down instruments (i.e., this was a simulated single pilot operation).

- This "head-out" performance degradation is clearly demonstrated in the JAR-AWO criteria as well. The JARAWO criteria is the same 1 dot glideslope exceedance, but the altitude range goes down to $100 \mathrm{ft} \mathrm{HAT}$. While statistical significance has not yet been computed, the comparison of the $200 \mathrm{ft}$ DA to the $100 \mathrm{ft}$ DA data above shows how performance changes when the pilots were "visual" (i.e., operations below $200 \mathrm{ft}$ HAT for the $200 \mathrm{ft}$ DA condition required that the pilot have identified at least the ALS). The performance changed for the HDD and the HUD display conditions. The pilots were likely attending to the visual acquisition task and were not focused on tracking the glideslope.

\subsection{Objective Landing Standards Application}

Existing performance-based landing standards were applied in the objective data analysis. These standards were drawn from numerous sources pertaining to the general concept of low-visibility approach and landings. However, none of these were written specifically as quantitative performance standards for Synthetic and Enhanced System operations. The analyses that follow examine their applicability for this purpose.

In Table IV, the selected quantitative landing performance standards are shown for longitudinal and lateral position at touchdown and sink rate at touchdown. Bank angle is typically included in the landing performance standards but was excluded from analysis in this paper since no operationally significant differences were found among the main factors as described in Section 4.3.2. In addition, many of these standards apply to a Monte Carlo analysis of automatic landing system performance and were not necessarily designed to apply to the analyses shown here (i.e., compliance for manual flight performance).

This experiment used a $1000 \mathrm{ft}$ from threshold aim point. For the simulated 757 aircraft, the outboard landing gear would be $70 \mathrm{ft}$ from the centerline when the fuselage (the recorded lateral landing position reported herein) is at $58 \mathrm{ft}$ lateral deviation from centerline, assuming no crab angle at touchdown. 
Table IV: Quantitative Landing Performance Standards

\begin{tabular}{|c|c|c|c|}
\hline & \multicolumn{3}{|c|}{ Landing Performance } \\
\hline & Longitudinal Position & Lateral Position & Touchdown Sink Rate \\
\hline $\begin{array}{l}\text { Automatic } \\
\text { Landing } \\
\text { Systems } \\
\text { (AC20 - 57A) } \\
\text { Reference } 23\end{array}$ & $\begin{array}{l}\text { Two-sigma longitudinal dispersion } \\
\text { should not exceed } 1500 \mathrm{ft} \text { total, but } \\
\text { need not be symmetrical about the } \\
\text { nominal point. By analysis, } \\
\text { longitudinal touchdowns should be } \\
\text { shown to be improbable }\left(10^{-6}\right) \\
\text { outside of a point at least } 200 \text { feet } \\
\text { beyond the threshold and that point } \\
\text { down the runway at which the pilot } \\
\text { is in a position to see at least } 4 \text { bars } \\
\text { (on } 100 \text { ' centers) of the } 3000 \text { foot } \\
\text { touchdown zone lights. }\end{array}$ & $\begin{array}{l}\text { Two-sigma lateral dispersion of } \\
\text { aircraft centerline at the main } \\
\text { gear should not exceed } 27 \mathrm{ft} \\
\text { either side of centerline By } \\
\text { analysis, lateral touchdowns } \\
\text { should be shown to be } \\
\text { improbable }\left(10^{-6}\right) \text { with the } \\
\text { outboard landing gear no closer } \\
\text { than five feet from the lateral } \\
\text { limits of a } 150 \text { foot runway }\end{array}$ & No guidance specified. \\
\hline $\begin{array}{l}\text { AC 120-28D, } \\
\text { Appendix 3, } \\
\text { Paragraph 6.3.1. } \\
\text { Reference } 19\end{array}$ & $\begin{array}{l}\text { No longitudinal touch down earlier } \\
\text { than a point on the runway } 200 \mathrm{ft} \text {. } \\
(60 \mathrm{~m}) \text { or beyond } 2700 \mathrm{ft} .(823 \mathrm{~m}) \\
\text { from threshold to a probability of } 1 \\
\times 10^{-6} \text {. }\end{array}$ & $\begin{array}{l}\text { No lateral touch down with the } \\
\text { outboard landing gear more than } \\
70 \mathrm{ft} .(21.3 \mathrm{~m}) \text { from runway } \\
\text { centerline to a probability of } 1 \mathrm{x} \\
10^{-6} .\end{array}$ & $\begin{array}{l}\text { No sink rate greater than } \\
\text { structural limit load to a } \\
\text { probability of } 1 \times 10^{-6} \text {. } \\
\text { One component of showing } \\
\text { structural load compliance is } \\
\text { that the sink rate at touch } \\
\text { down is not greater than } 10 \\
\text { feet per second. }\end{array}$ \\
\hline $\begin{array}{l}\text { JAR-AWO } \\
\text { AMC AWO } 231 \\
\text { Reference } 22\end{array}$ & $\begin{array}{l}\text { No longitudinal touch down earlier } \\
\text { than a point on the runway } 200 \mathrm{ft} \text {. } \\
(60 \mathrm{~m}) \text { or beyond } 2700 \mathrm{ft} .(823 \mathrm{~m}) \\
\text { from threshold to a probability of } 1 \\
\times 10^{-6} \text {. }\end{array}$ & $\begin{array}{l}\text { No lateral touch down with the } \\
\text { outboard landing gear more than } \\
70 \mathrm{ft} .(21.3 \mathrm{~m}) \text { from runway } \\
\text { centerline to a probability of } 1 \mathrm{x} \\
10^{-6} .\end{array}$ & $\begin{array}{l}\text { No sink rate greater than } \\
\text { structural limit load to a } \\
\text { probability of } 1 \times 10^{-6} \text {. }\end{array}$ \\
\hline
\end{tabular}

\subsubsection{Sink rate at Touchdown}

The main factor of RVR $(\mathrm{F}(2,97)=3.97, \mathrm{p}=0.022)$ and the second order interaction between DA and location $(\mathrm{F}(1$, $591)=5.68, \mathrm{p}=0.017$ ) were significant for sink rate at touchdown. The other main factors of content, location, ALS, and DA and $2^{\text {nd }}$ order interactions were not significant ( $p>0.05$ ). Post-hoc tests (SNK using $\alpha=0.05$ ) showed two overlapping subsets for sink rate at touchdown with the 3 RVR values: 1) $2400 \mathrm{ft}$ (mean= $-4.8 \mathrm{fps}$ ) and $1800 \mathrm{ft}$ (mean= $-5.1 \mathrm{fps}$ ) and 2) $1800 \mathrm{ft}$ (mean $=-5.1 \mathrm{fps})$ and $1200 \mathrm{ft}$ (mean $=-5.4 \mathrm{fps})$. Visual inspection of the data revealed that 29 of the 790 runs (or $3.7 \%$ of the runs) were not within the acceptable sink rate at touchdown criteria (-10 fps) and that 15 of these 29 "unacceptable" runs were flown by the one pilot. The other 14 "unacceptable" runs were spread among nine pilots.

Even though the pilots were not necessarily current in the B-757 aircraft to serve as evaluation pilots, $96 \%$ of the data were within acceptable sink rate limits. Visibility (i.e., RVR) provided the biggest influence (statistical significance) in sink rate at touchdown, but operationally, the differences were marginal.

\subsection{1. $\quad$ Centerline Maintenance}

The main factors of RVR $(F(2,77)=23.24, p<0.001)$, ALS $(F(2,50)=81.54, p<0.001)$, and $\mathrm{DA}(\mathrm{F}(1,23)=72.73, \mathrm{p}<0.001)$ and the second order interaction between DA and location $(F(2,591)=37.65, p<0.001)$ were highly significant for lateral distance from centerline (measured in feet). The other main factors (content and location) and the $2^{\text {nd }}$ order interactions were not significant $(\mathrm{p}>0.05)$ for this measure. Post-hoc tests (SNK using $\alpha=0.05$ ) showed two unique subsets for lateral distance from centerline with the 3 RVR values: 1) $1800 \mathrm{ft}$ (mean=4 ft left of centerline) and 2) $2400 \mathrm{ft}$ (mean= $8 \mathrm{ft}$ right of centerline) and $1200 \mathrm{ft}$ (mean=9 ft right of centerline). There were two unique subsets for ALS: 1) MALSR (mean=1 $\mathrm{ft}$ right of centerline) and 2) ALSF-2 and VFR (both means $=13 \mathrm{ft}$ right of centerline). In addition, pilots landed closer to the centerline with the $100 \mathrm{ft}$ DA (mean $=5 \mathrm{ft}$ right of centerline) than with the $200 \mathrm{ft}$ DA (mean=8 ft right of centerline). 


\subsubsection{Touchdown Zone Position}

The touchdown aim point position was located 1000 feet from the runway $18 \mathrm{R}$ threshold. There were no significant $(\mathrm{p}>0.05)$ effects for the main factors (content, location, RVR, ALS, and DA) or their interactions in the touchdown positions $(\mathrm{n}=790)$. The overall mean position was $639 \mathrm{ft}$ forward of the aim point with a standard deviation of $582 \mathrm{ft}$.

To be considered a successful landing, the touchdown position had to be between $-800 \mathrm{ft}$ aft of the aim point and +1700 $\mathrm{ft}$ forward of the aim point. Visual inspection of the data revealed that 36 out of the 780 runs (or $4.6 \%$ of the runs) were not within the acceptable landing criteria as they were greater than $1700 \mathrm{ft}$ forward of the aim point and that 18 of these "unacceptable" runs were completed by two pilots (9 runs/pilot). The remaining 18 runs were distributed among 7 pilots. $75 \%$ ( 27 out of 36 runs) of the unsuccessful landings were made with the 1200 RVR visibility level.

\subsubsection{Landing Performance Discussion}

$100 \%$ of the normal runs that ended with a landing were within the centerline criteria and $96 \%$ were within the sink rate at touchdown criteria for a successful landing as specified in AC $120-28 \mathrm{D} / \mathrm{Appendix} 3^{19}$ - namely, they were laterally within $+/-58$ feet of centerline and with a vertical speed at touchdown of less than $10 \mathrm{fps}$. RVR, ALS and DA were statistically significant for centerline maintenance, but operationally these differences (on the order of one to five feet) were negligible. The presence or location of SV imagery didn't have a significant effect on the pilot's ability to land on centerline.

Statistical analysis against the criteria using Table IV have not been completed, but cursory inspection of the data suggests that the criteria associated with $1 \times 10^{-6}$ probability requirements will not be met. In Figure 7, the touchdown data are shown, broken out by RVR. Included on this plot is the $+/-58$ lateral and $200 \mathrm{ft}$ to $2700 \mathrm{ft}$ longitudinal touchdown zone definition used in Table IV.
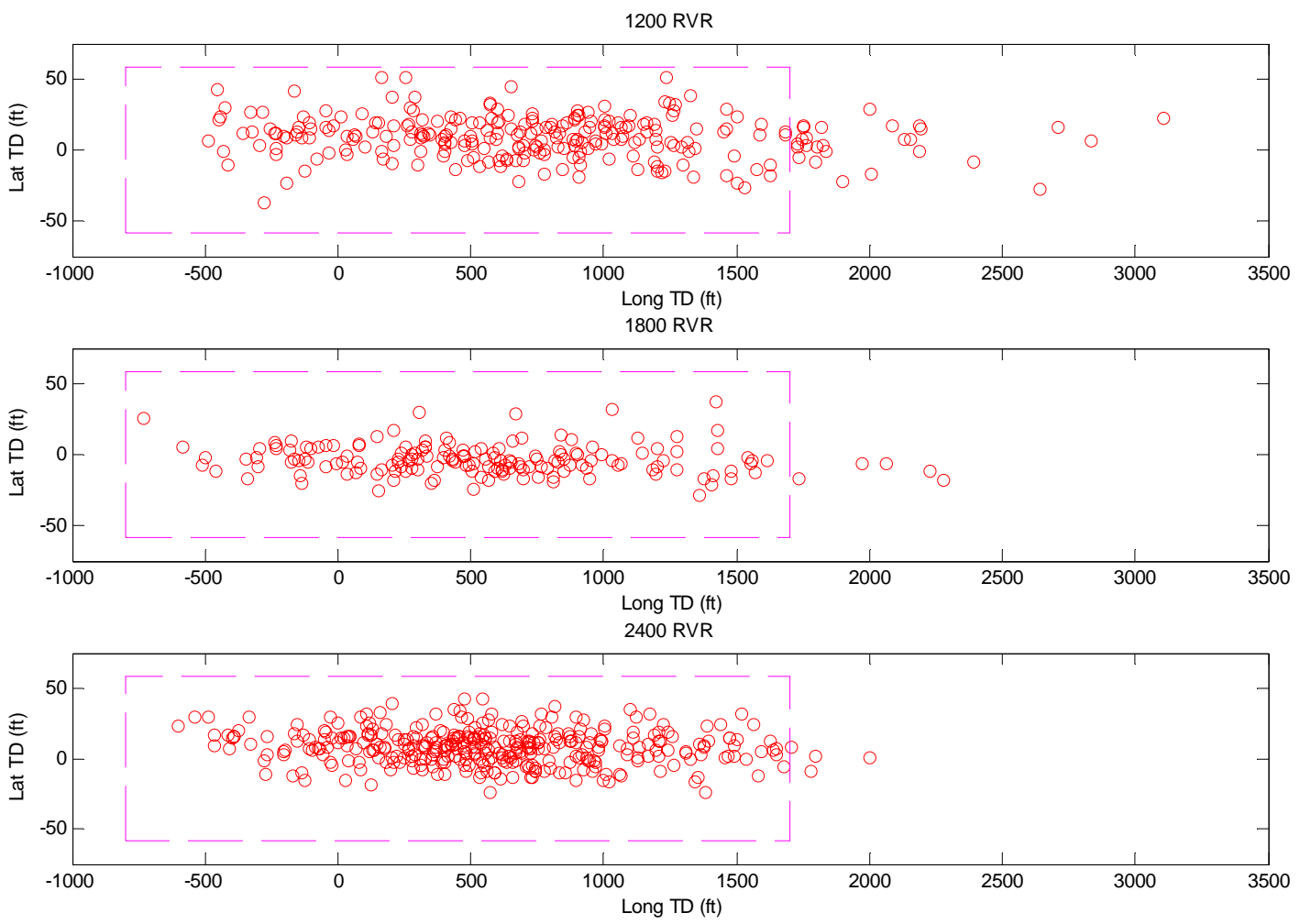

Figure 7. Landing Performance Data for 1200 RVR (top), 1800 RVR (middle), and 2400 RVR (bottom).

The data in Figure 7 shows the much higher propensity (but not statistically significant) to land within the "desired" touchdown zone with a 2400 RVR compared to the 1800 and $1200 \mathrm{ft}$ RVR visibility conditions. Since this phase of flight is strictly "visual" (based on the visibility and the operating criteria used in the test) no influence for SV was 
expected, or seen. In addition, no influence in HUD vs. HDD was seen. Somewhat surprisingly, no operational influence in ALS was found. The VFR lighting condition performance was comparable to the ALSF-2 lighting condition performance.

\section{CONCLUSIONS}

An experiment was conducted to evaluate SVS and SVS-related technologies to develop operational concepts for allweather approach and landing and to provide quantitative and qualitative information that could be used to develop criteria for all-weather approach and landing technologies such as synthetic vision. A Global Positioning System / Wide Area Augmentation System (GPS/WAAS) approach was simulated to provide precise approach guidance instead of an instrument landing system (ILS), and the "operational considerations" evaluated under this effort included reduced visibility, decision altitudes, and airport equipage requirements, such as approach lighting systems, for SVS-equipped and non-equipped aircraft. In addition, the role of display location (HDD versus HUD) in landing operations and the pilot decision-making process was also investigated.

Objective results from the present study showed that better approach performance was attainable with the HUD compared to the HDD. A slight performance improvement in HDD performance was shown when SV was added, as the pilots descended below $200 \mathrm{ft}$ to a $100 \mathrm{ft} \mathrm{DA}$, but this performance was not tested for statistical significance (nor was it expected to be statistically significant). The data also showed that precise glideslope tracking was lost once pilots went "visual" for the landing.

Further, the touchdown data showed that regardless of the display concept flown (SV HUD, Baseline HUD, SV HDD, Baseline HDD) a majority of the runs were within the performance-based defined approach and landing criteria in all the visibility levels, approach lighting systems, and decision altitudes tested. However, a small percentage (5\%) of runs were flown past the touchdown zone or with a harder landing than specified in the landing criteria. All runs ended safely in a full stop with adequate runway remaining. For this visual flight maneuver, RVR appeared to be the most significant influence in touchdown performance. The approach lighting system clearly impacted the pilot's ability to descend to $100 \mathrm{ft}$ HAT based on existing FAR 91.175 using a $200 \mathrm{ft}$ decision height, but did not appear to influence touchdown performance or approach path maintenance.

\section{REFERENCES}

1. National Aeronautics and Space Administration. (n.d.). Aviation Safety Program / Integrated Intelligent Flight Deck Technical Plan Summary. Retrieved October 3, 2007, from http://www.aeronautics.nasa.gov/nra pdf/iifd tech_plan_c1.pdf.

2. Federal Aviation Administration. (n.d.). Instrument Flight Procedures (IFP) Inventory Summary. Retrieved January 15, 2008, from http://avn.faa.gov/index.asp?xml=nfpo/inventory-summary.

3. Federal Aviation Administration. (n.d.). ILS Performance Classification - Report. Retrieved January 15, 2008, from http://avnwww.jccbi.gov/pls/datasheet prd/PRO ilsperform rpt.

4. Federal Aviation Administration. (n.d.). Navigation Services: Lighting Systems Group - MALSR. Retrieved January 15,2008 , from

http://www.faa.gov/about/office_org/headquarters_offices/ato/service_units/techops/navservices/lsg/malsr/

5. Federal Aviation Administration. (n.d.). GNSS Library - Briefings: Navigation Evolution Update to the RNAV Taskforce. Retrieved January 21, 2008, from

http://www.faa.gov/about/office_org/headquarters offices/ato/service units/techops/navservices/gnss/library/briefin gs/

6. Kramer, L .J., Arthur, J. J., Bailey, R. E., and Prinzel III, L. J. (2005). Flight Testing An Integrated Synthetic Vision System. In Proceedings of SPIE, Enhanced and Synthetic Vision 2005, Editor: Jacques G. Verly, Volume 5802, Paper 1, April 2005.

7. Arthur, J. J., Prinzel, L. J., Kramer, L. J., Bailey, R. E., and Parrish, R. V. (2003). CFIT Prevention Using Synthetic Vision. In Proceedings of SPIE, Enhanced and Synthetic Vision 2003, Editor: Jacques G. Verly, Volume 5018, Paper 16, April 2003.

8. Schiefele, J., Howland, D., Maris, J., Pschierer, C., Wipplinger, P., and Meuter, M. (2005) Human Factors Flight Trial Analysis for 3D SVS: Part II. In Proceedings of SPIE, Enhanced and Synthetic Vision 2005, Editor: Jacques G. Verly, Volume 5802, Paper 18, April 2005. 
9. Theunissen, E., and Rademaker, R. (2005) Human Factors Test \& Evaluation of an Integrated Synthetic Vision and Sensor-Based Flight Display System for Commercial and Military Applications. Paper presented at the NATO Research and Technology Organization, Human Factors and Medicine panel workshop entitled "Toward Recommended Methods for Testing and Evaluation of EV and E/SV-Based Visionic Devices", Williamsburg, VA, USA, 26-27 April 2005.

10. Kramer, L. J., Prinzel, L. J., Bailey, R. E., and Arthur, J. J. (2003). Synthetic Vision Enhances Situation Awareness And RNP Capabilities For Terrain-Challenged Approaches. Proceedings of the American Institute of Aeronautics and Astronautics Third Aviation Technology, Integration, and Operations Technical Forum, AIAA 2003-6814, 111, November 2003.

11. Kramer, L .J., Prinzel, L. J., Arthur, J. J., and Bailey, R. E. (2004). Pathway Design Effects On Synthetic Vision Head-Up Displays. SPIE. In Proceedings of SPIE, Enhanced and Synthetic Vision 2004, Editor: Jacques G. Verly, Volume 5424, Paper 8, April 2004.

12. Kramer, L. J., Williams, S. P., and Bailey, R. E. (2007). Synthetic Vision Systems Operational Considerations Evaluation. SPIE. In Proceedings of SPIE, Enhanced and Synthetic Vision 2007, Editor: Jacques G. Verly, Volume 6559, Paper 1, April 2007.

13. Merrick, V. K. and Jeske, J. A. (1995). Flightpath Synthesis and HUD Scaling for V/STOL Terminal Area Operations. NASA Technical Memorandum 110348, April 1995.

14. AIAA (1993). Guide to Human Performance Measurement. Washington D.C.: American Institute of Aeronautics and Astronautics.

15. Gallagher, Donald W. (2002). Reduced Approach Lighting Systems (ALS) Configuration Simulation Testing. Washington D.C.: Department of Transportation. DOT/FAA/AR-02/81.

16. Vidulich, M. A. and Hughes, E. R. (1991). Testing A Subjective Metric Of Situation Awareness. Proceedings of the Human Factors \& Ergonomics Society, $35^{\text {th }}$ Annual Meeting, 1307-1311, Santa Monica, CA: HFS.

17. Federal Aviation Administration Advisory Circular: Standard Operating Procedures for Flight Deck Crewmembers, AC 120-71A, Dated February 27, 2003.

18. Federal Aviation Administration: Instrument Rating Practical Test Standards for Airplane, Helicopter, and Powered Lift, FAA-S-8081-4D, Dated April 2004.

19. Federal Aviation Administration Advisory Circular: Criteria for Approval of Category III Weather Minima for Takeoff, Landing, and Rollout, AC-120-28D, Dated July 13, 1999.

20. Flight Safety Foundation: Approach and Landing Accident Reduction Tool-Kit. Retrieved February 7, 2007, from http://www.flightsafety.org/pdf/alar_guide.pdf.

21. Federal Aviation Administration Advisory Circular: Criteria For Approval Of Category I And Category II Weather Minima For Approach, AC120-29A, Dated August 12, 2002.

22. European Aviation Safety Agency, Joint Aviation Requirements, All-Weather Operations. Amendment 4, Dated February, 2007.

23. Federal Aviation Administration Advisory Circular: Automatic Landing Systems (ALS), AC20-57A, Dated Jan 12, 1971. 